\title{
Chromatographic Zinc Isotope Separation by Chelating Exchange Resin
}

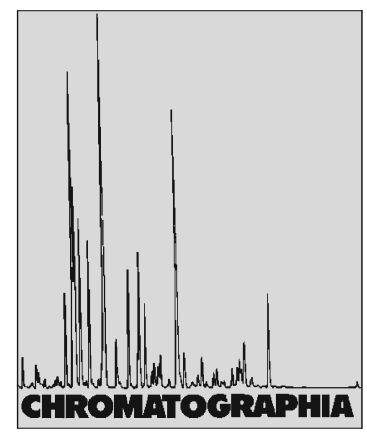

2010, 71, 195-199

\author{
Xingcheng Ding ${ }^{1, 凶}$, Masao Nomura ${ }^{2}$, Tatsuya Suzuki ${ }^{2}$, Yasuhiko Fujii ${ }^{2}$ \\ ${ }^{1}$ Institute of Nuclear Agricultural Sciences, Zhejiang University, 310029 Hangzhou, China; E-Mail: dingxch@zju.edu.cn \\ 2 Research Laboratory for Nuclear Reactors, Tokyo Institute of Technology, O-okayama, Meguro-ku, 152-8550 Tokyo, Japan
}

Received: 15 June 2009 / Revised: 22 October 2009 / Accepted: 11 November 2009

Online publication: 12 January 2010

\begin{abstract}
Zinc isotope separations were studied by displacement chromatography using the chelating properties of malate, citrate and lactate exchange resin and EDTA as ligands. After each chromatographic operation, the heavier zinc isotopes were found to preferentially fractionated into the carboxylate complex solution phase. The separation coefficients $(\varepsilon)$ for zinc isotope separation had the largest value and were obtained for the isotopic pairs ${ }^{68} \mathrm{Zn} /{ }^{64} \mathrm{Zn}$ $\left(7.16 \times 10^{-4}\right)$ and ${ }^{66} \mathrm{Zn} /{ }^{64} \mathrm{Zn}\left(3.08 \times 10^{-4}\right)$, respectively, at $298 \pm 1 \mathrm{~K}$. The separation coefficient per unit mass differences $(\varepsilon / \Delta M)$ for the isotopic pair of ${ }^{68} \mathrm{Zn} /{ }^{64} \mathrm{Zn}$ was found to range around $1.55 \times 10^{-4}$.
\end{abstract}

\section{Keywords}

Zinc isotope separation

Chelating exchange resin

Separation coefficient

Separation coefficient per unit mass differences

\section{Introduction}

Zinc is considered as a useful material for cooling water treatment in light water nuclear power plants. A trace amount of soluble zinc injected into the coolant water suppresses ${ }^{60} \mathrm{Co}$ buildup in water piping systems and reduces the gamma ray dose rate from the piping system carrying the coolant [1-6] and this method has been successfully applied to several nuclear reactors that were used for power generation. However, the use of natural zinc does not provide the maximum benefit due to the adverse effects that are brought about by an increase in radioactive ${ }^{65} \mathrm{Zn}$ levels caused by the neutron activation of ${ }^{64} \mathrm{Zn}$ in the reactor core. The use of depleted zinc, i.e., depleted in isotope ${ }^{64} \mathrm{Zn}$, was found to be more effective to reduce this radiation dose in the cooling water system. The separation of zinc isotopes is therefore of high interest within nuclear science and technology.

Nowadays, zinc isotopes can be obtained using the most advanced centrifuge technology in the world, but this method requires a relatively large amount of energy and therefore has economic restrictions. The present technique could not meet the increasing demands of the ${ }^{64} \mathrm{Zn}$ depleted zinc isotopes in the world. Compared to this physical method, chemical exchange methods utilizing equilibrium processes have been considered to require less energy consumption and present more economical and environmental clean advantages. The use of chromatographic techniques for the enrichment of isotopes has been regarded as a promising method for large scale production of enriched isotopes. Chromatography operated in the band displacement manner was found to be an efficient process and was characterized by maintaining the self-sharpening band boundaries at both migration band ends. Isotope separation based on ion exchange involves equilibrium formation between the stationary phase resin and the mobile phase solution [7]. The ion exchange displacement chromatography has been successfully applied to the 
Table 1. Chromatographic experimental conditions of zinc isotope fractionation using different ligands

\begin{tabular}{|c|c|c|c|c|}
\hline Complex system & $\mathrm{Zn}$-EDTA & $\mathrm{Zn}$-malate & $\mathrm{Zn}$-citrate & Zn-lactate \\
\hline Eluting agent & $\begin{array}{l}\left(\mathrm{NH}_{4}\right)_{2}-\mathrm{EDTA} \\
\left(0.1 \mathrm{~mol} \mathrm{~L}^{-1}\right. \\
\mathrm{pH}=7.5 \pm 0.2)\end{array}$ & $\begin{array}{l}\left(\mathrm{NH}_{4}\right)_{2}-\text { malate } \\
\quad\left(0.1 \mathrm{~mol} \mathrm{~L}^{-1}\right. \\
\mathrm{pH}=7.4 \pm 0.2)\end{array}$ & $\begin{array}{l}\left(\mathrm{NH}_{4}\right)_{3}-\text { citrate } \\
(0.1 \mathrm{~mol} \mathrm{~L}-1 \\
\mathrm{pH}=7.2 \pm 0.2)\end{array}$ & $\begin{array}{l}\mathrm{NH}_{4} \text {-lactate } \\
\quad\left(0.1 \mathrm{~mol} \mathrm{~L}^{-1}\right. \\
\mathrm{pH}=7.3 \pm 0.2)\end{array}$ \\
\hline Resin & \multicolumn{4}{|c|}{$\begin{array}{l}\text { Macroporous, particle size } 0.4-0.6 \mathrm{~mm} \text {, total exchange capacity } \geq 1.8 \mathrm{mmol} \mathrm{mL}^{-1} \text {, } \\
\text { water content } 48-56 \%,-\mathrm{CH}_{2}-\mathrm{N}\left(\mathrm{CH}_{2} \mathrm{COOH}\right)_{2} \text { functional group }\end{array}$} \\
\hline Temperature (K) & \multicolumn{4}{|c|}{$298 \pm 1$} \\
\hline Feed solution & \multicolumn{4}{|c|}{$0.1 \mathrm{~mol} \mathrm{~L}{ }^{-1} \mathrm{ZnCl}_{2}+0.01 \mathrm{~mol} \mathrm{~L}^{-1} \mathrm{HCl}$ solution } \\
\hline Migration length $(\mathrm{m})$ & \multirow{2}{*}{\multicolumn{4}{|c|}{$\begin{array}{l}9.5 \\
6.0+0.1\end{array}$}} \\
\hline Flow rate $\left(\mathrm{mL} \mathrm{h}^{-1}\right)$ & & & & \\
\hline
\end{tabular}

separation of isotopes of various elements in complex formation systems especially for those using hydroxycarboxylates as ligands [8-12]. Malate, citrate, lactate and EDTA are important ligands that can form a wide variety of complex species with metal ions [13, 14]. Chelating exchange resins have a relatively large zinc adsorption capacity and may be caused by the functional group of the chelating resin [15]. The present study continued the effort to carry out zinc isotope separation by the use of chelating exchange resin. Chromatographic experiments were designed using the four ligands mentioned above in order to elucidate the isotope effect present during zinc complexation. Emphasis was placed on the impact of ligands on the separation coefficient $(\varepsilon)$ and the separation coefficient per unit mass differences $(\varepsilon / \Delta M)$ observed during the separation processes.

\section{Experimental}

\section{Chromatographic Process}

The chromatographic system used in the present study consisted of five Pyrex columns (100 cm long and $1.0 \mathrm{~cm}$ i.d.) and a high pressure pump (Nihon Seimitsu NP-KX-100) that was used for controlling the flow rate of the feeding solution. Columns were connected in series with a Teflon tube. In order to monitor the column pressure, a pressure gauge with a safety device was placed between the first column and the pump. The temperature was set at $298 \pm 1 \mathrm{~K}$ throughout the experiments by circulating thermostated water through an extension water jacket out of the columns. An automatic fraction collector (FRC-2100, Iwaki Asahi Techno Glass, Tokyo, Japan) was used for collecting the effluents into small fractions (ca. $1.0 \mathrm{~mL}$ ). The columns were packed with the commercially available chelating exchange resin D850 (Hangzhou Zhengguang Resin Co., Hangzhou, China). The functional group of this macroporous exchange resin was based on $-\mathrm{CH}_{2}-\mathrm{N}\left(\mathrm{CH}_{2} \mathrm{COOH}\right)_{2}$ and the particle size of the resin was $0.4-0.6 \mathrm{~mm}$. At the beginning of the chromatographic operation packed column was conditioned by elution with $2.0 \mathrm{~mol} \mathrm{~L}{ }^{-1} \mathrm{HCl}$ solution in order to remove impurities followed by redistilled water. A $0.1 \mathrm{~mol} \mathrm{~L}^{-1} \mathrm{ZnCl}_{2}$ with $0.01 \mathrm{~mol} \mathrm{~L}^{-1}$ $\mathrm{HCl}$ solution were used as feeding solution until the length of the zinc adsorption band became ca. $50 \mathrm{~cm}$ long. The zinc band was then eluted at a flow rate of $6.0 \pm 0.1 \mathrm{~mL} \mathrm{~h}^{-1}$ using $0.1 \mathrm{~mol} \mathrm{~L}^{-1}$ ligand solutions. These were prepared from malic acid, citric acid, lactic acid, and EDTA, with ammonia solution, respectively. The eluting solutions were adjusted to each corresponding $\mathrm{pH}$ value and transferred to the top of the column. After collection of the zinc fractions the resin was regenerated to the $\mathrm{H}^{+}$form using $2.0 \mathrm{~mol} \mathrm{~L}^{-1} \mathrm{HCl}$ solution in order to continuously run the five packed columns. The operating conditions for the zinc isotope separation is summarized in Table 1.

\section{Chemical and Isotopic Analysis}

The zinc concentrations obtained from each fraction was measured by an atomic adsorption spectrophotometer (ANA-
$182 \mathrm{~F}$ type) using the emission line at $213.9 \mathrm{~nm}$ and sensitivity calibration was performed before measurements. The mass determination of the feed solution and fraction samples taken from the front band region were performed by inductively coupled plasma mass spectrometry (ICP-MS, X7 Series and supported by Thermo Electron Corporation) with the zinc concentration of $30 \mathrm{ppb}$ diluted with $0.5 \% \mathrm{HNO}_{3}$. The dwell time for ${ }^{64} \mathrm{Zn},{ }^{66} \mathrm{Zn}$ and ${ }^{68} \mathrm{Zn}$ was $10 \mathrm{~ms}$ and for ${ }^{68} \mathrm{Zn}$ and ${ }^{70} \mathrm{Zn}$ was $20 \mathrm{~ms}$. For each isotope measurement, the number of scans were 200 and the measurement error was within $0.2 \%$.

\section{Results and Discussion}

The mechanism of zinc isotope separation by chelating exchange chromatography is illustrated in Fig. 1.

Chromatography was conducted in a band displacement manner. At the rear band boundary of zinc ions, the adsorbed zinc ions were released from the resin, as indicated in Eq. 1, and formed complexes with the ligand supplied by the eluent where superscript bars denote the resin phase:

$\overline{\mathrm{Zn}^{2+}}+\left(\mathrm{NH}_{4}\right)_{2} \mathrm{~L} \rightarrow \overline{2 \mathrm{NH}_{4}^{+}}+\mathrm{ZnL}$

During the elution through the zinc adsorption band, the isotope exchange reaction (Eq. 2) took place repeatedly between zinc carboxylate complexes in the external solution phase and the zinc ions on the resin phase:

$\overline{\mathrm{H}^{2+}}{ }^{2+}{ }^{\mathrm{L}} \mathrm{Zn} \mathrm{L} \rightleftarrows \overline{\mathrm{Lnn}^{2+}}+{ }^{\mathrm{H}} \mathrm{Zn} \mathrm{L}$

where the superscripts $\mathrm{H}$ and $\mathrm{L}$ denote the heavier and lighter zinc isotopes, respectively. 
When the zinc carboxylate complex species reached the front boundary of the zinc adsorption band, the zinc complexes dissociated and the free zinc ions were re-adsorbed onto the resin phase (Eq. 3):

$\overline{\mathrm{Zn} \mathrm{L}}+2 \mathrm{H}^{+} \rightarrow \overline{\mathrm{H}_{2} \mathrm{~L}}+\mathrm{Zn}^{2+}$

The results obtained by the above mentioned chemical reactions and isotopic analysis are plotted in Fig. 2.

The zinc concentration found in the effluent fraction corresponded to the front band of zinc adsorption in the columns. The same analyses were performed for the other three ligands that were found to give similar results (not shown). Since the stability constant of zinc complex species is larger than that of ammonium complex species $[16,17]$ and the total selectivity of the chelating exchange resin for zinc ions is higher than that for protons, the Eq. 1 and Eq. 3 at rear and front boundaries tended to proceed to the right side and resulted in the formation of sharp boundaries at both edges of the band.

It could be obviously found from the profile of isotopic ratios (Fig. 2) that the heavier zinc isotopes were enriched at the front edge and the lighter zinc isotopes enriched at the rear boundary by the present chelating exchange resin. The isotope exchange reaction represented by Eq. 2 concentrated the heavier zinc isotopes in aqueous solution. The results were interpreted by the mechanism that the heavier zinc isotopes were preferentially fractionated into the zinc complex species present in aqueous solution and moved down at a relatively faster velocity to the front edge while the lighter zinc isotopes were retained in the form of zinc ions on the resin and eluted down at a lower velocity, resulting in the accumulation at the rear boundary. The results suggested that the equilibrium constant of Eq. 2 should be larger than unit one in each operated system. This was consistent with the prediction that the heavier zinc isotopes were expected to fractionation into the strong bound chemical species based on the theory of isotope effects in molecular vibration [10].

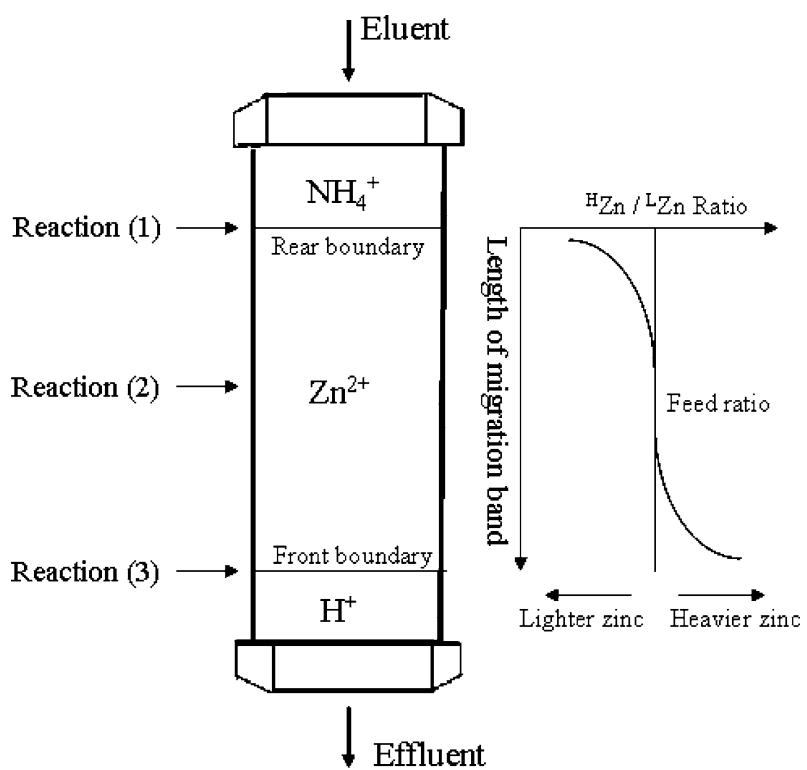

Fig. 1. The fractionation mechanism and isotope ratio curve of zinc using chelating exchange chromatography

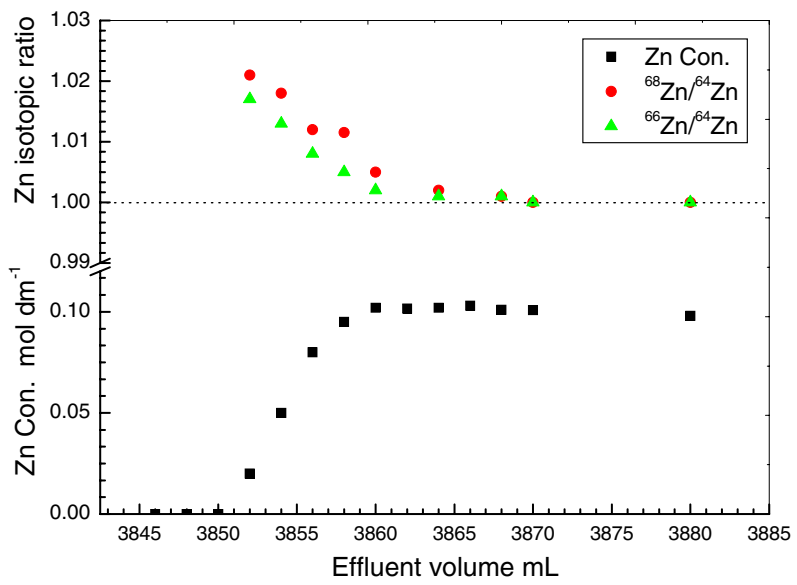

Fig. 2. Chromatographic profile of zinc effluent concentration and isotopic ratios using the citrate ligand

The isotope separation coefficient $\varepsilon$ is used to evaluate chromatographic performance and can be calculated based on Eq. 4 which was derived by Spedding and Kakihana [18, 19]:

$\varepsilon=\alpha-1=\sum \frac{q_{i}\left|R_{i}-R_{o}\right|}{Q R_{o}\left(1-R_{o}\right)}$

where $\alpha$ refers to the isotope fractionation factor, or the single stage separation factor; $q$ is the amount of zinc in fraction sample, $Q$ the total amount of adsorbed zinc on the resin, $R_{i}$ the isotopic percentage of ${ }^{\mathrm{H}} \mathrm{Zn}$, and the sub- scripts $i$ and $o$ are the fraction number and the original sample, respectively.

The separation coefficients were calculated in each operation from the isotopic enrichment curve of the front boundary and are listed in Table 2 .

Each ligand gave distinct $\varepsilon$ values and EDTA was found to result in the strongest coordination bond with zinc ions as judged by the relatively large $\varepsilon$ value [20]. When compared to the lactate, citrate and malate ligand systems, the different $\varepsilon$ value might relate to the complex chemical species in solution. It was reported that 
Table 2. Separation coefficients of zinc in ligand complex systems by chelating exchange resin

\begin{tabular}{|clllll|}
\hline & & Zn-EDTA & Zn-malate & Zn-citrate & Zn-lactate \\
\hline Separation coefficient & ${ }^{68} \mathrm{Zn} /{ }^{64} \mathrm{Zn}$ & 7.16 & 5.52 & 6.17 & 5.96 \\
$\left(\varepsilon \times 10^{-4}\right)$ & ${ }^{66} \mathrm{Zn} /{ }^{64} \mathrm{Zn}$ & 3.08 & 2.51 & 2.68 & 2.83 \\
\hline
\end{tabular}

Table 3. Chromatographic separation coefficients of metal ions in ligand complex systems

\begin{tabular}{|c|c|c|c|c|c|}
\hline Metal ion & $\begin{array}{l}\text { Measured } \\
\text { isotopic } \\
\text { pair }\end{array}$ & $\begin{array}{l}\text { Complex } \\
\text { formation } \\
\text { system }\end{array}$ & $\mathrm{T}(\mathrm{K})$ & $\begin{array}{l}\text { Separation } \\
\text { coefficient, } \\
\varepsilon\left(\times 10^{-4}\right)\end{array}$ & Reference \\
\hline $\mathrm{Zn}^{2+}$ & $68 / 64$ & $\begin{array}{l}\text { Malate } \\
\text { Citrate } \\
\text { Lactate } \\
\text { EDTA }^{4-}\end{array}$ & 298 & $\begin{array}{l}5.52 \\
6.17 \\
5.96 \\
7.16\end{array}$ & Present work \\
\hline $\mathrm{VO}^{2+}$ & $50 / 51$ & $\begin{array}{l}\text { Malate } \\
\text { Lactate } \\
\text { Citrate }\end{array}$ & 298 & $\begin{array}{l}1.0 \\
2.4 \\
2.2\end{array}$ & $\begin{array}{r}{[10]} \\
{[9]} \\
{[9]}\end{array}$ \\
\hline $\mathrm{Cu}^{2+}$ & $63 / 65$ & $\begin{array}{l}\text { Malate } \\
\text { EDTA }^{4-}\end{array}$ & $\begin{array}{l}312 \\
323\end{array}$ & $\begin{array}{l}2.8 \\
0.13\end{array}$ & {$[23]$} \\
\hline $\mathrm{Gd}^{3+}$ & $158 / 160$ & $\begin{array}{l}\text { Malate } \\
\text { EDTA }^{4-}\end{array}$ & $\begin{array}{l}312 \\
332\end{array}$ & $\begin{array}{l}0.092 \\
0.25\end{array}$ & $\begin{array}{l}{[25]} \\
{[25]}\end{array}$ \\
\hline $\mathrm{UO}_{2}{ }^{2+}$ & $235 / 238$ & $\begin{array}{l}\text { Malate } \\
\text { EDTA }^{4-}\end{array}$ & $\begin{array}{l}298 \\
298\end{array}$ & $\begin{array}{l}2.2 \\
0.6\end{array}$ & $\begin{array}{l}{[26]} \\
{[27]}\end{array}$ \\
\hline
\end{tabular}

the existence of binuclear complexes of metal ions was probably the reason why the separation coefficient had a large value in the ligand system [21]. In an uranyl carboxylate complex system the existence of binuclear $\mathrm{UO}_{2}{ }^{2+}$ complexes might create the condition for large isotope fractionation and the separation coefficients followed the order malate $>$ citrate $=$ tartrate $>$ lactate $[22,23]$. On the contrary, the separation coefficients of vanadyl carboxylate system followed the inverse order lactate $>$ citrate $>>$ malate [9]. Table 3 presents the separation coefficient $\varepsilon$ and the related data of the isotopic pair of ${ }^{68} \mathrm{Zn} /{ }^{64} \mathrm{Zn}$ obtained in this work along with the results reported from the $\mathrm{VO}^{2+}, \mathrm{Cu}^{2+}, \mathrm{Gd}^{3+}$ and $\mathrm{UO}_{2}{ }^{2+}$ in malate and $\mathrm{EDTA}^{4-}$ ligand exchange systems [9, 10, 24-27].

Regarding the isotopic pair ${ }^{68} \mathrm{Zn} /{ }^{64} \mathrm{Zn}$ (Table 3 ) the separation coefficients found for lactate and citrate were slightly larger than those observed in a malate system and the $\varepsilon$ value with corresponding ligands obtained in the present work was much larger than that in vanadium system. Apart from the complex structure of zinc and vanadium with those ligands, the large mass difference between ${ }^{68} \mathrm{Zn}$ and ${ }^{64} \mathrm{Zn}$ could also contribute to the forma- tion of a relatively large separation coefficient. Zinc was found to display a much larger separation coefficient when compared with separation coefficients determined for $\mathrm{Cu}^{2+}, \mathrm{Gd}^{3+}, \mathrm{UO}_{2}{ }^{2+}$ (Table 3). For a zinc/EDTA ligand a larger value was observed in comparison with the other three ligands and as far as $\mathrm{Cu}^{2+}$ and $\mathrm{UO}_{2}{ }^{2+}$ were concerned, the separation coefficients in EDTA were found smaller than those observed in a malate system. The different metal complex structure in ligands and the $\mathrm{pH}$ value of the solution used in the present work might have significant impact on results. Further experiments were needed in order to elucidate the mechanism involved in the formation of zinc isotope separation coefficient using different ligand systems.

In general, the isotope effect or the isotope separation coefficient depended on the temperature. Theoretically, $\varepsilon$ is proportional to $\Delta M$ and inversely proportional to the square of both the atomic weight $M$ and the absolute temperature $T$ [26]:

$$
\varepsilon \propto \Delta M / M^{2} T^{2}
$$

Table 4 provides an overview of zinc isotope separation coefficient per unit mass differences using a number of different exchange resins [28-31].

It can be seen that each type of resin had different $\varepsilon / \Delta M$ values. The average $\varepsilon / \Delta M$ value for the isotopic pair of ${ }^{68} \mathrm{Zn} /{ }^{64} \mathrm{Zn}$ found in the present study was $1.55 \times 10^{-4}$ which was in agreement with our previous publications using benzo crown resins [31]. When this type of resin is used the cavity size can affect the $\varepsilon / \Delta M$ value significantly, especially when using the benzo-12-crown-4 resin. Benzo-15-crown-5 resin with $0.5 \mathrm{~mol} \mathrm{~L}^{-1}$ zinc chloride was determined to have the largest value (Table 4). It was shown that with the same benzo crown resin and feed solution [30], the $\varepsilon / \Delta M$ value was affected by operation temperature where a high temperature had a small value in alignment with Eq. 5. Ban et al. [12] performed the zinc isotope separation by using a strongly acidic exchange resin and obtained a value for $\varepsilon / \Delta M$ where the isotope effect occurred during cation exchange between the acidic resin and liquid phase. The present study indicated that the determined $\varepsilon / \Delta M$ value was much larger than that of Ban et al. [12] which meant that the present chelating exchange resin might form a more stable binuclear complex with zinc ions and could successfully applied to the zinc isotope separation.

\section{Conclusion}

Zinc isotope separations were studied by displacement chromatography in malate, citrate, lactate and EDTA systems. The zinc isotope fractionation was confirmed and the lighter isotope was found to be preferentially located on the resin stationary phase. Separation coefficients were calculated for each tested system where the EDTA ligand was found to make a more stable coordination bond with zinc ions that resulted in large $\varepsilon$ values. Polymerization of zinc in ligand complex systems might affect the isotope fractionation. The average $\varepsilon / \Delta M$ value for the isotopic pair of ${ }^{68} \mathrm{Zn} /{ }^{64} \mathrm{Zn}$ was determined to be $1.55 \times 10^{-4}$ which was in agreement with that obtained from benzo crown resins and much larger than 
Table 4. Separation coefficient per unit mass differences $(\varepsilon / \Delta M)$ for the isotopic pair of ${ }^{68} \mathrm{Zn} /{ }^{64} \mathrm{Zn}$ using different exchange resins

\begin{tabular}{|c|c|c|c|c|}
\hline Resin type & Feed solution & $\begin{array}{l}\text { Temperature } \\
(\mathrm{K})\end{array}$ & $\begin{array}{l}{ }^{68} \mathrm{Zn} /{ }^{64} \mathrm{Zn} \\
\varepsilon / \Delta M\left(\times 10^{-4}\right)\end{array}$ & Reference \\
\hline Benzo-12-crown-4 resin & $0.5 \mathrm{~mol} \mathrm{~L}^{-1} \mathrm{ZnCl}_{2}$ & 298 & 1.12 & [28] \\
\hline Benzo-15-crown-5 resin & $0.5 \mathrm{~mol} \mathrm{~L}^{-1} \mathrm{ZnCl}_{2}$ & 298 & 2.02 & {$[28,31]$} \\
\hline Benzo-15-crown-5 resin & $0.08 \mathrm{~mol} \mathrm{~L}^{-1} \mathrm{ZnCl}_{2}$ & 323 & 1.32 & [29] \\
\hline Benzo-15-crown-5 resin & $0.05 \mathrm{~mol} \mathrm{~L}^{-1} \mathrm{ZnCl}_{2}$ & 313 & 1.68 & [30] \\
\hline Benzo-15-crown-5 resin & $0.05 \mathrm{~mol} \mathrm{~L}^{-1} \mathrm{ZnCl}_{2}$ & 343 & 1.42 & {$[30]$} \\
\hline Benzo-18-crown-6 resin & $0.5 \mathrm{~mol} \mathrm{~L}^{-1} \mathrm{ZnCl}_{2}$ & 298 & 1.98 & [28] \\
\hline Dibenzo-18-crown-6 resin & $0.5 \mathrm{~mol} \mathrm{~L}^{-1} \mathrm{ZnCl}_{2}$ & 298 & 1.60 & {$[28,31]$} \\
\hline Strongly acidic cation exchange resin & $0.05 \mathrm{~mol} \mathrm{~L}^{-1} \mathrm{Zn}\left(\mathrm{NO}_{3}\right)_{2}$ & 333 & 0.80 & [12] \\
\hline \multirow[t]{4}{*}{ Chelating exchange resin } & $0.1 \mathrm{~mol} \mathrm{~L}^{-1} \mathrm{ZnCl}_{2}$ with EDTA solution & 298 & 1.79 & Present work \\
\hline & $0.1 \mathrm{~mol} \mathrm{~L}^{-1} \mathrm{ZnCl}_{2}$ with malate solution & & 1.38 & \\
\hline & $0.1 \mathrm{~mol} \mathrm{~L}^{-1} \mathrm{ZnCl}_{2}$ with citrate solution & & 1.54 & \\
\hline & $0.1 \mathrm{~mol} \mathrm{~L}^{-1} \mathrm{ZnCl}_{2}$ with lactate solution & & 1.49 & \\
\hline
\end{tabular}

that determined in strongly acidic cation exchange resins.

\section{Acknowledgment}

The present work was financially supported in part by the project (project code: J20080399) of the Ministry of Education, P. R. China.

\section{Open Access}

This article is distributed under the terms of the Creative Commons Attribution Noncommercial License which permits any noncommercial use, distribution, and reproduction in any medium, provided the original author(s) and source are credited.

\section{References}

1. Mochizuki K, Nagata T, Ogawa N (2000) Proceedings of the 8th symposium on Water Chemistry for Nuclear Reaction Systems. Bournemouth, UK, p 142

2. Wood CJ (1989) EPRI Report/NP-6168, Electric Power Research Institute (EPRI)
3. Marble WJ, Cowan RL, Wood CJ (1986) Proceedings of the 4th symposium on Water Chemistry for Nuclear Reaction Systems. Bournemouth, UK, p 113

4. Marble WJ, Wood CJ, Leighty CE, Green TA (1986) Proceedings of 1986 Joint ASME/ANS Nuclear Power Conference, $\mathrm{p} 144$

5. Asakura Y, Nagase M, Uchida S (1989) J Nucl Sci Technol 26:1112-1120

6. Hosokawa H, Nagase M (2004) J Nucl Sci Technol 41:682-689

7. Bigeleisen J, Mayer MG (1947) J Chem Phys 15:261-265

8. Oi T, Kakihana H (1992) In: Fujii Y, Ishida T, Takeuchi H (eds) Bull Tokyo Inst Technol (Special issue 1, Tokyo), p 343

9. Zhang Y, Nomura M, Aida M, Fujii Y (2003) J Chromatogr A 989:175-182

10. Zhang Y, Nomura M, Ban Y, Fujii Y (2003) Polyhedron 22:1377-1383

11. Matin MA, Nomura M, Fujii Y, Chen J (1998) Sep Sci Technol 33:1075-1087

12. Ban $Y$, Aida $Y$, Nomura M, Fujii $Y$ (2002) J Ion Exch 13:46-52

13. Goodin TW (ed) (1968) The metabolic roles of citrate. Academic Press, New York

14. Pedrosa de Jesus JD (1987) In: Wilkinson G, Gillard RD, McCleverty JA (eds) Comprehensive Coordination Chemistry, vol 2. Pergamon Press, Oxford, p 461

15. Ding X, Nomura M, Fujii Y (2009) Prog Nucl Energy. doi:10.1016/j.pnucene.2009. 06.003

16. Helena M, Teixiera SF, Pessoa JC, Boas LFV (1992) Polyhedron 11:697-702
17. Sillen LG (1971) Stability Constants, supplement No. 1, Chemical Society, London

18. Spedding FH, Powell JE, Svec HJ (1955) J Am Chem Soc 77:6125-6130

19. Kahihana H, Kanaki T (1969) Bull Tokyo Inst Technol 90:77

20. Davidenko NK (1964) Russ J Inorg Chem 9:859-863

21. Nomura M, Higuchi N, Fujii Y (1996) J Am Chem Soc 118:9127-9130

22. Nakagawa A, Sakuma Y, Okamoto M (1983) J Chromatogr 256:231-242

23. Kim HY, Kakihana M, Aida M, Kogure K, Nomura M, Fujii Y (1984) J Chem Phys 81:6266-6271

24. Matin M, Ismail I, Nomura M, Fujii Y (2002) Sep Sci Technol 37:2129-2142

25. Ismail I, Matin M, Nomura M, Begum S, Aida M, Fujii Y (2002) J Ion Exch 13:4045

26. Chen J, Nomura M, Fujii Y, Kawakami F, Okamoto F (1992) J Nucl Sci Technol 29:1086-1092

27. Rutenberg A, Drury J (1969) J Inorg Nucl Chem 31:2289-2293

28. Ding $X$, Suzuki T, Nomura M, Sugiyama Y, Kaneshiki T, Fujii Y (2006) Bull Chem Soc Jpn 79:1389-1392

29. Ding X, Nomura M, Fujii Y (2007) J Nucl Sci Technol 44:623-627

30. Zhang Y, Fukuda Y, Nomura M, Fujii Y, Oi T (2006) J Nucl Sci Technol 43:415418

31. Ding X, Nomura M, Suzuki T, Sugiyama Y, Kaneshiki T, Fujii Y (2006) J Chromatogr A 1113:182-185 